\title{
Sleep disorders and their relationship to other psychiatric disorders in women with breast cancer: a case-control study
}

\author{
Romany H. Gabra ${ }^{1 *}$ (D) and Doaa F. Hashem²
}

\begin{abstract}
Background: Breast cancer is the most frequent cancer among women, impacting 2.1 million women each year. The aim of the study is to determine prevalence of sleep disorders among patients with breast cancer, its correlation with different psychological symptoms and the ability of such symptoms to predict sleep disorders among those patients. The current study is a case-control study compromised of 153 participants, 93 breast cancer patients versus 60 cross-matched healthy control persons recruited from the outpatient clinic of Oncology Department-Assiut University Hospital. Arabic versions of Beck's Depression Inventory, symptom checklist, and Sleep Disorder Scale were used to evaluate depression, obsession, sensitivity, anxiety, hostility, phobic anxiety, paranoia ideation, psychoticism, and sleep disorders, respectively. The correlation of this data with clinical and social variables of these patients and the effect of such variables on each other were also determined.

Results: A statistically higher prevalence of sleep disorders and depression was reported among breast cancer patients compared to the control group. Also, patients with breast cancer scored statistically higher mean scores in somatization, obsession, sensitivity, anxiety, and phobic anxiety than those of the control group.

Conclusions: Prevalence of sleep disorders, depression, obsession, sensitivity, anxiety, hostility, phobic anxiety, paranoia ideation, and psychoticism among breast cancer patients poses a challenge to the treatment of such patients. Misdiagnosis and mismanagement lead to poor treatment outcomes of both cancer disease and psychiatric disorders.
\end{abstract}

Keywords: Sleep disorders, Psychiatric disorders, Breast cancer and woman

\section{Background}

Breast cancer is the most frequent cancer among women, impacting 2.1 million women each year; it also causes the greatest number of cancer-related deaths among women. Recent studies suggest that sleep disturbance is considered one of the most common disorders among breast cancer patients. Several evidence show that $30 \%$ to $70 \%$ of adult cancer patients reported experiencing one or more sleep disturbances $[1,2]$, a

\footnotetext{
* Correspondence: romanyhosny@med.aun.edu.eg; https://scholar.google. com.eg/citations?view_op=list_works\&hl=ar\&user=06d916wAAAAJ 1 Department of Neurology and Psychiatry, Assiut University Hospitals, Box 71516, Assiut, PO, Egypt

Full list of author information is available at the end of the article
}

percentage that is twice as high as those reported in the general population $[3,4]$.

Survival women with breast cancer suffer many different conditions that may influence their emotional welfare and mental health. About 30\% of breast cancer survivors experience chronic pain several years after treatment. This chronic pain is commonly related to development of depression. Thus, pain and depression are common symptoms in many serious diseases and carry a risk of self-perceived poor health, poor quality of life, and premature mortality [4].

Sleep disorders were considered a common phenomenon in breast cancer patients. Several other psychiatric disorders were associated with sleep

\section{Springer Open}

(-) The Author(s). 2021 Open Access This article is licensed under a Creative Commons Attribution 4.0 International License, which permits use, sharing, adaptation, distribution and reproduction in any medium or format, as long as you give appropriate credit to the original author(s) and the source, provide a link to the Creative Commons licence, and indicate if changes were made. The images or other third party material in this article are included in the article's Creative Commons licence, unless indicated otherwise in a credit line to the material. If material is not included in the article's Creative Commons licence and your intended use is not permitted by statutory regulation or exceeds the permitted use, you will need to obtain permission directly from the copyright holder. To view a copy of this licence, visit http://creativecommons.org/licenses/by/4.0/. 
disorders such as depression, anxiety, psycho-somatic symptoms, and pain [5]. In general, sleep disorders were associated with a worsening of the general health condition leading to changes in cognitive functions, depression, and emotional instability [6].

Sleep problems are commonly reported as the most burdensome symptoms among cancer survivors $[7,8]$, up to $79 \%$ of the cases reported sleep disturbance during treatment period. Also, serious physical and psychological symptoms are associated with these sleep problems in cancer patients, such as lower quality of life, more depressive symptoms, poor social and occupational functioning, and early mortality [9-11].

Also, depression is considered as one of the most frequent psychiatric comorbidities in breast cancer patients. Studies show its average prevalence ranges from 12 to $25 \%$ [12]. Sleep disturbance is considered as one manifestation of depression manifestation (hypersomnia or insomnia) or as a separate disorder.

Emotional distress in cancer patients is a common phenomenon that negatively impacts the quality of life and carries elevated risk of mortality [12]. Cancer is a serious illness that is usually aggressive and requires very invasive treatments. Thus, since the event is evaluated as a threat, an anxious emotional reaction arises. Cancer is perceived as a significant loss (loss of health, psychological well-being, life expectancy, etc.) that will result in sadness and increased somatization, obsession, sensitivity, anxiety, and phobic anxiety, all of which can trigger or increase depression and sleep disorders [13].

The current study is a case control study that aims to evaluate prevalence of different sleep disorders among breast cancer patients, also, we examine the prevalence of different other psychiatric symptoms among those patients and its relation to sleep problems. Special emphasis on some clinical and social characteristics of the patients and correlation with the prevalence of those psychiatric symptoms was also performed.

Also, investigating the role of such psychological symptoms is predicting sleep disorders among breast cancer patients.

\section{Methods}

\section{Sample}

The study includes 93 breast cancer patients versus 60 age and sex cross-matched healthy control persons.

The current study was carried out at the outpatient clinic, Oncology Department-Assiut University Hospital. All patients coming for follow-up at the outpatient clinic (from June 2019 to March 2020) were selected after accepting to participate in the study and after proper explanation of the aim and tools of the study. An informed signed consent was obtained from all patients. Patients were interviewed by a well-trained psychologist for evaluation.

All patients and control were examined for previous history of psychiatric disorders and those who have a history of any psychiatric disorders were excluded from the study.

\section{Study tools \\ Beck's Depression Inventory}

The Beck's Depression Inventory (BDI-II) [14], created by Aaron T. Beck, is a 21-question multiplechoice, self-report inventory, is one of the most widely used psychometric tests for measuring the severity of depression.

Assessment of depression was performed by the Arabic version of Beck's Depression Inventory [15].

In the current study, the reliability coefficient of the "Beck" list for depression ((BDI-II) Arabic version) was verified using Cronbach's alpha coefficient.

\section{Symptom checklist}

A symptom checklist (SCL-90-R) is a tool that enables clinicians and researchers to quickly estimate the presence of different psychiatric disorder symptoms [16]. It is designed to evaluate a broad range of psychological problems and symptoms of psychopathology.

The primary symptom dimensions being assessed are somatization, obsessive-compulsive, interpersonal sensitivity, depression, anxiety, hostility, phobic anxiety, paranoid ideation, and psychoticism.

The verification of the Arabic version of symptom checklist was done by Al-Buhairi, A R 2005, and was verified using factor analysis [17].

Verification of validity and reliability of the Arabic version of symptom checklist was done by Al-Buhairi, A R 2005.

\section{Sleep Disorder Scale (SDS)}

The Sleep Disorder Scale (SDS) is a questionnaire that is widely used in developed countries to measure daytime sleepiness and diagnose sleep disorders.

The validity and reliability of the Arabic version of SDS were performed by Arnout and Boshra [18].

\section{Statistical analysis}

Data analysis was performed using the Statistical Package for Social Science (SPSS) in its nineteenth version.

Quantitative data analysis was used in this study. The results were analyzed using descriptive and 
inferential statistics. Categorical variables were described by number and percent $(N, \%)$, whereas continuous variables were described by mean and standard deviation (mean, SD). Independent sample ( $T$ test) was used for comparison between samples. The Pearson correlation coefficient was used to determine the relationship between psychological symptoms and sleep disorders and simple regression analysis was used to determine the ability of independent variables to predict the dependent variables.

\section{Results}

The current study includes 153 participants, 93 breast cancer patients versus 60 cross-matched healthy control persons.

The age group of the studied sample was 23:79 years. About $97.8 \%$ of the patients were unemployed compared to $66.7 \%$ of the control group. On the other hand, $2.2 \%$ of the patients have jobs compared to $33.3 \%$ of the control group (Table 1).

Regarding the marital status, $77.4 \%$ of the patients were married, $43 \%$ of the married cases got a good husband's support compared to $34.4 \%$ of who did not get good husband's support. Most of the patients had treatment duration from 1 month to 4 years $(68.8 \%)$, the rest of them had more than 4 years of treatment. Also, about $39.8 \%$ of the patients had recurrence of the disease, compared to $60.2 \%$ of them who had no recurrence of breast cancer or its metastasis. The entire patient group had received chemotherapy, while only $52.7 \%$ got sessions of radiotherapy (Table 2).

Assessment of depressive symptoms using the Arabic version of Beck's Depression Inventory revealed that most of the studied sample were depressed $(39.8 \%$ of patients suffer from mild depression, $53.8 \%$ of patients suffer from moderate depression, and $2.2 \%$ suffer from

Table 1 Socio-demographic data of a sample of breast cancer patients and control group

\begin{tabular}{|c|c|c|c|c|c|}
\hline \multirow[t]{2}{*}{ Variables } & & \multicolumn{2}{|c|}{ Patients $(N=93)$} & \multicolumn{2}{|c|}{ Control $(N=60)$} \\
\hline & & $N$ & $\%$ & $N$ & $\%$ \\
\hline \multirow[t]{3}{*}{ Age } & $23-40$ & 23 & 24.7 & 15 & 25 \\
\hline & $41-55$ & 34 & 36.6 & 31 & 51.7 \\
\hline & 56 and over & 36 & 38.7 & 14 & 23.3 \\
\hline \multirow[t]{2}{*}{ Work } & Work & 2 & 2.2 & 20 & 33.3 \\
\hline & No work & 91 & 97.8 & 40 & 66.7 \\
\hline \multirow[t]{4}{*}{ Marriage } & Single & 3 & 3.2 & 5 & 8.3 \\
\hline & Married & 72 & 77.4 & 52 & 86.7 \\
\hline & Divorced & 4 & 4.3 & 1 & 1.7 \\
\hline & Widowl & 14 & 15.1 & 2 & 3.3 \\
\hline
\end{tabular}

Table 2 The clinical data for a sample of breast cancer patients $(\mathrm{N}=93)$

\begin{tabular}{|c|c|c|c|}
\hline \multirow[t]{2}{*}{ Variables } & & \multicolumn{2}{|c|}{$\begin{array}{l}\text { Patient } \\
(N=93)\end{array}$} \\
\hline & & $N$ & $\%$ \\
\hline \multirow{2}{*}{$\begin{array}{l}\text { Did you have psychiatric disorders } \\
\text { before you had breast cancer? }\end{array}$} & Yes & 0 & 0 \\
\hline & No & 93 & 100 \\
\hline \multirow[t]{2}{*}{ Supporting family } & Supporting family & 40 & 43.0 \\
\hline & $\begin{array}{l}\text { Without the } \\
\text { support of a } \\
\text { family }\end{array}$ & 32 & 34 \\
\hline Duration & $\begin{array}{l}\text { From month to } 3 \\
\text { years }\end{array}$ & 64 & 68.8 \\
\hline Treatment & $\begin{array}{l}\text { From } 4 \text { years or } \\
\text { more }\end{array}$ & 29 & 31.2 \\
\hline \multirow[t]{2}{*}{ Recurrence } & Recurrence & 37 & 39.8 \\
\hline & No recurrence & 56 & 60.2 \\
\hline \multirow[t]{2}{*}{ Sessions of chemotherapy } & 0-6 session & 50 & 53.8 \\
\hline & $7 \leq$ more & 43 & 46.2 \\
\hline \multirow[t]{2}{*}{ Sessions of radiotherapy } & 0 sessions & 44 & 47.3 \\
\hline & $1 \leq$ more & 49 & 52.7 \\
\hline
\end{tabular}

severe depression). The control group showed that $25.6 \%$ of them did not suffer from any symptoms of depression, while $10.9 \%$ suffered from mild depression, and $1.9 \%$ suffers from moderate depression with no cases of severe depression (Table 3).

The evaluation of the presence of different sleep disorders in the studied sample using Sleep Disorder Scale shows that patients with breast cancer scored significantly higher mean scores of some domains of sleep disorder (insomnia, hypersomnia, interrupted sleep, nightmares, and total sleep disorders) than the control group. However, there were no statistically significant differences between breast cancer patients and control group in night dismay and sleep walking disorder (Table 4).

Assessment of different psychiatric symptoms by SCL shows the following: Patients with breast cancer scored statistically higher mean scores in depression somatization, obsession, sensitivity, anxiety, and phobic

Table 3 Beck depression inventory scores in patients with breast cancer and the control group (total $N=153$ )

\begin{tabular}{|c|c|c|c|c|c|}
\hline \multicolumn{2}{|l|}{ Variables } & \multicolumn{2}{|c|}{ Patient $(N=93)$} & \multicolumn{2}{|c|}{ Control $(N=60)$} \\
\hline & & $N$ & $\%$ & $N$ & $\%$ \\
\hline \multirow[t]{4}{*}{ Beck scale } & Normal & 4 & 4.3 & 40 & 25.6 \\
\hline & Mild depression & 37 & 39.8 & 17 & 10.9 \\
\hline & Moderate depression & 50 & 53.8 & 3 & 1.9 \\
\hline & Severe depression & 2 & 2.2 & 0 & 0 \\
\hline
\end{tabular}


Table 4 Mean scores of Beck depression and SCL in patients with breast cancer-control group

\begin{tabular}{lllllll}
\hline Scale & Subscale & $\begin{array}{l}\text { Control } \\
\text { Mean } \pm \text { Std }\end{array}$ & $\begin{array}{l}\text { Patients } \\
\text { Mean } \pm \text { Std }\end{array}$ & & \multicolumn{1}{c}{$\begin{array}{l}\text { Cl 95\% } \\
\text { value }\end{array}$} \\
\hline Beck depression & Beck depression & $11 \pm 5.05$ & $20.26 \pm 3.75$ & 12.99 & .000 & $\{-10.67873:-7.8590\}$ \\
SCLR & Somatization & $1.455 \pm .713$ & $1.836 \pm .423$ & 4.14 & .000 & $\{-.56205:-1.9889\}$ \\
& Obsession & $1.376 \pm .7333$ & $1.781 \pm .375$ & 4.50 & .000 & $\{-.58348:-.22762\}$ \\
& Sensitivity & $1.244 \pm .569$ & $1.801 \pm .376$ & 7.29 & .000 & $\{-.70810:-.40634\}$ \\
& Anxiety & $1.158 \pm .557$ & $1.405 \pm .394$ & 3.20 & .002 & $\{-.39932: 09476\}$ \\
& Hostility & $.755 \pm .351$ & $.758 \pm .465$ & .036 & .972 & $\{-.14156: 1.13654\}$ \\
& Phobic anxiety & $.692 \pm .295$ & $.860 \pm .535$ & 2.21 & .028 & $\{-.31679:-.01792\}$ \\
& Paranoia ideation & $1.327 \pm .684$ & $1.353 \pm .431$ & .280 & .780 & $\{-.20341: 15287\}$ \\
& Psychoticism & $.983 \pm .620$ & $1.047 \pm .320$ & .837 & .404 & $\{-.21500: 08704\}$ \\
\hline
\end{tabular}

anxiety than those of the control group. On the other hand, there were no statistically significant differences between the patients and the control sample in terms of hostility, paranoia ideation, and psychoticism (Table 5).

Correlating family support with the psychiatric symptomatology reveals the following: Breast cancer patients without supporting family scored significantly higher mean scores of all domains of sleep disorder except hypersomnia, night dismay. Breast cancer patients without supporting family cored significantly higher mean scores of depression and somatization than the group of patients having supporting family. On the other hand, group of patients with supporting family scored significantly lower mean scores of sensitivities than the group without supporting family (Tables 6 and 7).

Correlating disease characteristics with the psychiatric symptomatology shows that patients with breast

Table 5 Frequency of sleep disorders between patients with breast cancer versus control group

\begin{tabular}{|c|c|c|c|c|c|c|}
\hline \multirow[t]{2}{*}{ Scale } & \multirow[t]{2}{*}{ Subscale } & \multirow{2}{*}{$\begin{array}{l}\text { Control } \\
\text { Mean } \\
\pm \text { Std }\end{array}$} & \multirow{2}{*}{$\begin{array}{l}\text { Patients } \\
\text { Mean } \\
\pm \text { Std }\end{array}$} & \multirow{2}{*}{$T$} & \multirow[t]{2}{*}{$P$ value } & \multirow[t]{2}{*}{$\mathrm{Cl} 95 \%$} \\
\hline & & & & & & \\
\hline \multirow[t]{7}{*}{$\begin{array}{l}\text { Sleep } \\
\text { disorder }\end{array}$} & Insomnia & $\begin{array}{l}12.77 \pm \\
2.80\end{array}$ & $\begin{array}{l}18.19 \pm \\
3.68\end{array}$ & 9.73 & .000 & $\begin{array}{l}\{-6.52827: \\
-4.32550\}\end{array}$ \\
\hline & Hypersomnia & $\begin{array}{l}8.050 \pm \\
2.683\end{array}$ & $\begin{array}{l}8.935 \pm \\
1.892\end{array}$ & 2.39 & .018 & $\begin{array}{l}\{-1.61679: \\
-.15417\}\end{array}$ \\
\hline & $\begin{array}{l}\text { Interrupted } \\
\text { sleep }\end{array}$ & $\begin{array}{l}8.650 \pm \\
1.447\end{array}$ & $\begin{array}{l}12.634 \pm \\
2.426\end{array}$ & 11.46 & .000 & $\begin{array}{l}\{-4.67111: \\
-3.29771\}\end{array}$ \\
\hline & Nightmares & $\begin{array}{l}7.150 \pm \\
1.857\end{array}$ & $\begin{array}{l}8 \pm \\
2.231\end{array}$ & 2.45 & .015 & $\begin{array}{l}\{-1.53485: \\
-.16515\}\end{array}$ \\
\hline & $\begin{array}{l}\text { Night } \\
\text { dismay }\end{array}$ & $\begin{array}{l}6.083 \pm \\
2.444\end{array}$ & $\begin{array}{l}6.602 \pm \\
2.579\end{array}$ & 1.24 & .217 & $\begin{array}{l}\{-1.34584: \\
.30820\}\end{array}$ \\
\hline & $\begin{array}{l}\text { Sleep } \\
\text { walking } \\
\text { disorder }\end{array}$ & $\begin{array}{l}5.100 \pm \\
2.260\end{array}$ & $\begin{array}{l}5.655 \pm \\
1.862\end{array}$ & 1.65 & .100 & $\begin{array}{l}\{-1.21907: \\
.10724\}\end{array}$ \\
\hline & $\begin{array}{l}\text { Total sleep } \\
\text { disorder }\end{array}$ & $\begin{array}{l}46.15 \pm \\
5.61\end{array}$ & $\begin{array}{l}60.02 \pm \\
13.09\end{array}$ & 7.75 & .000 & $\begin{array}{l}\{-17.40643: \\
-.01792\}\end{array}$ \\
\hline
\end{tabular}

cancer metastatic recurrence scored significantly higher mean scores of all domains of sleep disorder (insomnia, hypersomnia, interrupted sleep, nightmares, night dismay, sleep walking, total sleep disorder) as well as depression and phobic anxiety and psychoticism than the group of patients with no recurrence (Tables 8 and 9).

There is a significant positive correlation between depression and all types of sleep disorders (insomnia, hypersomnia, nightmares disorder, night dismay, and sleep walking disorder). Moreover, significant positive correlations were found between all sleep disorder subscales and SCL-R except that of the sensitivity domain (Table 10).

Simple regression analysis of the data shows significant predictors for depression and anxiety to all sleep disorders subscales. On the other hand, somatization, hostility, and psychoticism predict higher scores of all sleep disorders subscales except night dismay. Also, obsession predicts higher scores of all sleep disorders subscales except that of sleep cycle rhythm disorder. Phobic anxiety also predicts all sleep disorders subscales except that of hypersomnia. Paranoid ideation also predicts higher scores of sleep disorders subscales except nightmare disorder and night dismay (Table 11).

Simple regression analysis of the data shows positive significant predictors for psychological symptoms to all sleep disorder subscales. Depression ranked the first in predicting total sleep disorders, it got $25 \%$ of the variance in total sleep disorders, and it also ranked the second in night dismay prediction, where it got $24 \%$ of variance in night dismay and the third and fourth order in predicting sleep walking and insomnia. It got $22 \%$ in the variance of sleep walking and $20 \%$ in the variance of insomnia. Obsession ranked the fifth in the predictive ability of sleep walking disorder, as it got $18 \%$ in the variance of sleep walking disorder (Table 11). 
Table 6 Difference in Beck depression and SCL scores between breast cancer patients with or without family support ( $N=93$ )

\begin{tabular}{|c|c|c|c|c|c|c|}
\hline Scale & Subscale & $\begin{array}{l}\text { Supporting family } \\
\text { Mean } \pm \text { Std }\end{array}$ & $\begin{array}{l}\text { Without supporting family } \\
\text { Mean } \pm \text { Std }\end{array}$ & $T$ & $\begin{array}{l}P \\
\text { value }\end{array}$ & $\mathrm{Cl} 95 \%$ \\
\hline Beck depression & Beck depression & $18.175 \pm 1.781$ & $21.031 \pm 4.185$ & 3.902 & .000 & $\{-4.31:-1.39\}$ \\
\hline \multirow[t]{8}{*}{ SCLR } & Somatization & $1.735 \pm .487$ & $1.940 \pm .264$ & 2.136 & .036 & $\{-.396:-.135\}$ \\
\hline & Obsession & $1.685 \pm .450$ & $1.825 \pm .292$ & 1.518 & .134 & $\{-.32399: .04399\}$ \\
\hline & Sensitivity & $1.894 \pm .172$ & $1.642 \pm .541$ & 2.779 & .007 & $\{.0711: .432\}$ \\
\hline & Anxiety & $1.385 \pm .445$ & $1.396 \pm .327$ & 1.26 & .900 & $\{-1.9990: 1.7615\}$ \\
\hline & Hostility & $.750 \pm .469$ & $.677 \pm .308$ & .757 & .452 & $\{-.1194: .26508\}$ \\
\hline & Phobic anxiety & $.700 \pm .426$ & $.924 \pm .629$ & 1.796 & .077 & $\{-.47299: .02478\}$ \\
\hline & Paranoid ideation & $1.279 \pm .531$ & $1.322 \pm .338$ & .404 & .687 & $\{-.25958: .17208\}$ \\
\hline & Psychoticism & $.995 \pm .333$ & $1.01 \pm .288$ & .151 & .880 & $\{-.15995: .13745\}$ \\
\hline
\end{tabular}

\section{Discussion}

The current case-control study examines the associations between different psychiatric domains and sleep disorders in breast cancer patients and correlates them with some of the patients and disease characteristics.

Breast cancer and its invasive treatment option are perceived as a loss of health or body integrity, or even a challenge for the loss of life itself. Such loss may be a triggering force for the development of depression. Also, pain associated with the disease itself and with its treatment is considered as a factor to increase the liability to develop depression and anxiety.

Assessment of prevalence of depression among patients with breast cancer revealed that those patients have significantly higher scores of depressions than those of the control group. A data that is common in different similar studies [19-21].

Facing a malignancy is a big shock and distress for the patient and is considered by the many as a life crisis which causes psychological instability ranging from anxiety to depression.

Several previous studies show that family support is an important determinant to protect from depression in cancer patients. The current results show that patients with poor family support are manifested with higher levels of depression and anxiety than those with high family support (mean scores of $21.0 \pm 4.185$ versus $18.2 \pm 1.781$ ) [22]. Also, patients with recurrent disease after treatment had a higher prevalence of depression than those without recurrence. This can be explained by the burden of treatment (radio and chemotherapy). Such findings are like those previous data obtained by Jovana and Milutin [23].

Several previous studies show that family support is an important determinant to protect from depression in cancer patients. The current results show that patients with poor family support are manifested with higher levels of depression and anxiety than those with high family support (mean scores of $21.0 \pm 4.185$ versus $18.2 \pm 1.781$ ) [22]. Also, patients with recurrent disease after treatment had a higher prevalence of depression than those without recurrence. This can be explained by the burden of treatment (radio and chemotherapy). Such findings are like those previous data obtained by Jovana and Milutin [23].

Table 7 Difference in sleep disorders mean scores in breast cancer patients with or without family support ( $N=93)$

\begin{tabular}{|c|c|c|c|c|c|c|}
\hline Scale & Subscale & $\begin{array}{l}\text { With family support } \\
\text { Mean } \pm \text { Std }\end{array}$ & $\begin{array}{l}\text { Without family support } \\
\text { Mean } \pm \text { Std }\end{array}$ & $T$ & $\begin{array}{l}P \\
\text { value }\end{array}$ & $\mathrm{Cl} 95 \%$ \\
\hline \multirow[t]{7}{*}{ Sleep disorder } & Insomnia & $17.150 \pm 2.326$ & $18.687 \pm 3.987$ & 2.044 & .045 & $\{-3.037:-.037\}$ \\
\hline & Hypersomnia & $8.475 \pm 1.280$ & $9.156 \pm 2.156$ & 1.666 & .100 & $\{-1.497202: .13452\}$ \\
\hline & Interrupted sleep & $12.050 \pm 1.782$ & $13.125 \pm 2.587$ & 2.083 & .041 & $\{-1.075: .5160\}$ \\
\hline & Nightmares disorder & $7.450 \pm 1.584$ & $8.406 \pm 2.353$ & 2.054 & .044 & $\{-1.884:-.027\}$ \\
\hline & Night dismay & $6.125 \pm 1.284$ & $6.843 \pm 2.941$ & 1.390 & .169 & $\{-1.74982: 31232\}$ \\
\hline & Sleep walking disorder & $4.950 \pm 1.299$ & $5.968 \pm 2.055$ & 2.561 & .013 & $\{-1.812:-.225\}$ \\
\hline & Total sleep disorder & $56.200 \pm 6.381$ & $62.187 \pm 14.930$ & 2.291 & .025 & $\{-11.199:-.775\}$ \\
\hline
\end{tabular}


Table 8 Different mean scores of Beck depression and SCL in breast cancer patients with or without history of disease recurrence $(N=93)$

\begin{tabular}{lllllll}
\hline Scale & Subscale & $\begin{array}{l}\text { Recurrence } \\
\text { Mean } \pm \text { Std }\end{array}$ & $\begin{array}{l}\text { No recurrence } \\
\text { Mean } \pm \text { Std }\end{array}$ & \multicolumn{1}{c}{$\begin{array}{l}\boldsymbol{P} \text { Cl 95\% } \\
\text { value }\end{array}$} \\
\hline Beck depression & Beck depression & $23.729 \pm 2.950$ & $17.982 \pm 2.136$ & 10.895 & .000 & $\{4.699: 6.795\}$ \\
SCLR & Somatization & $1.927 \pm .400$ & $1.775 \pm .430$ & 1.720 & .089 & $\{-02361: 32887\}$ \\
& Obsession & $1.854 \pm .248$ & $1.733 \pm .434$ & 1.522 & .132 & $\{-.03670: 27695\}$ \\
& Sensitivity & $1.717 \pm .476$ & $1.857 \pm .282$ & 1.770 & .080 & $\{-.29587: .01702\}$ \\
& Anxiety & $1.470 \pm .390$ & $1.362 \pm .395$ & 1.293 & .199 & $\{-.05781: 27336\}$ \\
& Hostility & $.864 \pm .507$ & $.687 \pm .426$ & 1.819 & .072 & $\{-.01630: 37103\}$ \\
& Phobic anxiety & $1.057 \pm .729$ & $.507 \pm .475$ & 3.020 & .003 & $\{.328: 108\}$ \\
& Paranoid ideation & $1.450 \pm .285$ & $1.288 \pm .497$ & 1.789 & .077 & $\{-.01785: 34137\}$ \\
& Psychoticism & $1.135 \pm .989$ & $.329 \pm .303$ & 2.192 & .031 & $\{.145: 066\}$ \\
\hline
\end{tabular}

Cancer-related stress is considered as a precipitating factor for the development of different psychiatric symptoms. Evaluating different psychiatric symptoms using symptom checklist (somatization, obsession, sensitivity, anxiety, phobic anxiety, hostility, paranoia ideation and psychoticism) shows that patients with breast cancer scored statistically higher mean scores in somatization, obsession, sensitivity, anxiety, and phobic anxiety than those of the control group. Other different studies showed comparable results $[24,25]$.

The severe physical and psychological stress, exerted by the cancer itself and its treatment modalities (chemo and radiotherapy), makes depression, somatization, obsession, sensitivity, anxiety, and phobic anxiety symptoms more prevalent in women with breast cancer.

The general-distress factors have been demonstrated in seven mood and anxiety disorders (major depression, dysthymia, agoraphobia, social phobia, simple phobia, GAD, and panic disorder) [26].

Sleep is essential to the maintenance of physiological and psychological health in humans.
Evaluating the presence of sleep disorders in the studied sample using Sleep Disorder Scale shows that patients with breast cancer scored a significantly higher mean score of insomnia, hypersomnia, interrupted sleep, nightmares, and total sleep disorder than in control group. These data consistent with the data showing that about $30 \%$ to $70 \%$ of the adult population suffering from cancer reported one or more sleep problems [2].

Patients with breast cancer are one of the most common examples of sleep disturbance suffering [27-29]. A study done by Harris reported that breast cancer patients had sleep problems before diagnosis and sleep disorders aggravated after the diagnosis and ongoing therapy [29].

Such sleep disorders are not only affected by the cancer diagnosis itself but also correlated with the disease staging and with the type of treatment used (radiotherapy and chemotherapy). Also, the current results show that sleep disorders in cancer patients have a higher prevalence in patients with metastasizing and recurrent cancer than those without recurrence of the tumors (Table 9).

Table 9 Different mean scores of sleep disorders in breast cancer patients with or without history of disease recurrence ( $N=93$ )

\begin{tabular}{lllllll}
\hline Scale & Subscale & $\begin{array}{l}\text { Recurrence } \\
\text { Mean } \pm \text { Std }\end{array}$ & $\begin{array}{l}\text { No recurrence } \\
\text { Mean } \pm \text { Std }\end{array}$ & & \multicolumn{2}{c}{$\begin{array}{l}\boldsymbol{P} \text { Cl 95\% } \\
\text { value }\end{array}$} \\
\hline Sleep disorder & Insomnia & $19.540 \pm 4.975$ & $17.303 \pm 2.114$ & 2.987 & .004 & $\{.749: 3.724\}$ \\
& Hypersomnia & $9.621 \pm 2.453$ & $8.482 \pm 1.235$ & 2.959 & .004 & $\{.37451: 1.90445\}$ \\
& Interrupted Sleep & $13.513 \pm 3.114$ & $12.053 \pm 1.622$ & 2.957 & .004 & $\{.47935: 2.44053\}$ \\
& Nightmares disorder & $9.000 \pm 2.788$ & $7.339 \pm 1.455$ & 3.755 & .000 & $\{.782: 2.539\}$ \\
& Night dismay & $7.567 \pm 3.625$ & $5.964 \pm 1.220$ & 3.064 & .003 & $\{.56399: 2.64257\}$ \\
& Sleep walking disorder & $6.540 \pm 2.640$ & $4.928 \pm 1.109$ & 4.064 & .000 & $\{.824: 2.399\}$ \\
& Total sleep disorder & $65.783 \pm 18.470$ & $56.071 \pm 5.483$ & 3.705 & .000 & $\{4.540: 14.920\}$ \\
\hline
\end{tabular}


Table 10 Correlation between Beck depression and SCL R and Sleep Disorder Scale among woman with breast cancer ( $N=93$ )

\begin{tabular}{|c|c|c|c|c|c|c|c|c|c|}
\hline \multirow[t]{2}{*}{ sleep disorder } & \multirow{2}{*}{$\begin{array}{l}\text { Beck } \\
\text { depression }\end{array}$} & \multicolumn{8}{|l|}{ SCL R } \\
\hline & & Somatization & Obsession & Sensitivity & Anxiety & Hostility & $\begin{array}{l}\text { Phobic } \\
\text { anxiety }\end{array}$ & Paranoia ideation & Psychoticism \\
\hline Insomnia & $.445^{* *}$ & $.272^{* *}$ & $.343^{* *}$ & .035 & $.326^{* *}$ & $.268^{* *}$ & $.380^{* *}$ & $.250^{*}$ & $.363^{* *}$ \\
\hline Hypersomnia & $.406^{* *}$ & $.237^{*}$ & $.243^{*}$ & .654 & $.297^{* *}$ & $.243^{*}$ & .198 & $.243^{*}$ & $.233^{*}$ \\
\hline Interrupted sleep & $.444^{* *}$ & $.267^{* *}$ & .198 & .049 & $.319^{* *}$ & $.225^{*}$ & $.318^{* *}$ & $.230^{*}$ & $.220^{*}$ \\
\hline Nightmare disorder & $.407^{* *}$ & $.303^{* *}$ & $.347^{* *}$ & .088 & $.213^{* *}$ & $.315^{* *}$ & $.403^{* *}$ & .169 & $.330^{* *}$ \\
\hline Night dismay & $.494^{* *}$ & .068 & $.248^{*}$ & .077 & $.222^{*}$ & .172 & $.275^{* *}$ & .005 & .191 \\
\hline $\begin{array}{l}\text { Sleep walking } \\
\text { disorder }\end{array}$ & $.478^{* *}$ & $.386^{* *}$ & $.426^{* *}$ & .023 & $.327^{* *}$ & $.242^{*}$ & $.253^{*}$ & $.225^{*}$ & $.362^{* *}$ \\
\hline Total sleep disorder & $.502^{* *}$ & $.306^{* *}$ & $.339^{* *}$ & .009 & $.338^{* *}$ & $.275^{* *}$ & $.354^{* *}$ & $.211^{*}$ & $.324^{* *}$ \\
\hline
\end{tabular}

(Value $\left.^{*}=.05 \&^{* *}=.01\right)$

Table 11 Results of a simple regression analysis of depression and psychological symptoms in predicting sleep disorders in breast cancer patients $(N=93)$

\begin{tabular}{|c|c|c|c|c|c|c|c|}
\hline Predictive variables & Predicted variables & $R$ & $R$ Square & $B$ & Beta & $F$ & $T$ \\
\hline \multirow[t]{7}{*}{ Beck depression } & Insomnia & .445 & 198. & .436 & .445 & 22.487 & 4.742 \\
\hline & Hypersomnia & .406 & .165 & .204 & .406 & 17.931 & 4.235 \\
\hline & Interrupted sleep & .407 & .165 & .262 & .407 & 18.016 & 4.245 \\
\hline & Nightmare disorder & .444 & .198 & .246 & .444 & 22.403 & 4.733 \\
\hline & Night dismay & .494 & .244 & .339 & .494 & 29.406 & 5.423 \\
\hline & Sleep walking disorder & .478 & .229 & .257 & .478 & 26.986 & 5.195 \\
\hline & Total sleep disorder & .502 & .252 & 1.736 & .502 & 30.666 & 5.538 \\
\hline \multirow[t]{6}{*}{ Somatization } & Insomnia & .272 & .074 & 2.364 & .272 & 7.245 & 2.692 \\
\hline & Hypersomnia & .237 & .056 & 1.058 & .237 & 5.393 & 2.322 \\
\hline & Interrupted sleep & .267 & .071 & 1.533 & .579 & 7.006 & 2.647 \\
\hline & Nightmare disorder & .303 & .092 & 1.598 & .303 & 9.207 & 3.034 \\
\hline & Sleep walking disorder & .386 & .149 & 1.847 & .462 & 15.963 & 3.995 \\
\hline & Total sleep disorder & .306 & .049 & 9.559 & .306 & 9.429 & 3.071 \\
\hline \multirow[t]{6}{*}{ Obsession } & Insomnia & .343 & .118 & 3.367 & .343 & 12.134 & 3.483 \\
\hline & Hypersomnia & .243 & .059 & 1.226 & .243 & 5.717 & 2.391 \\
\hline & Nightmare disorder & .347 & .120 & 2.060 & .585 & 12.422 & 3.525 \\
\hline & Night dismay & .284 & .062 & 1.707 & .284 & 5.983 & 2.446 \\
\hline & Sleep walking disorder & .426 & .181 & 2.297 & .426 & 20.177 & 4.492 \\
\hline & Total sleep disorder & .339 & .115 & 11.937 & .339 & 11.841 & 3.441 \\
\hline \multirow[t]{7}{*}{ Anxiety } & Insomnia & .326 & .106 & 3.039 & .326 & 10.805 & 3.287 \\
\hline & Hypersomnia & .297 & .088 & 1.424 & .297 & 8.811 & 2.968 \\
\hline & Interrupted sleep & .319 & .101 & 1.957 & .319 & 10.280 & 3.206 \\
\hline & Nightmare disorder & .312 & .097 & 1.763 & .312 & 9.812 & 3.134 \\
\hline & Night dismay & .222 & .049 & 1.450 & .222 & 4.713 & 2.171 \\
\hline & Sleep walking disorder & .327 & .107 & 1.674 & .327 & 10.867 & 3.297 \\
\hline & Total sleep disorder & .338 & .114 & 11.308 & .338 & 11.753 & 3.428 \\
\hline
\end{tabular}


Table 11 Results of a simple regression analysis of depression and psychological symptoms in predicting sleep disorders in breast cancer patients ( $N=93$ ) (Continued)

\begin{tabular}{|c|c|c|c|c|c|c|c|}
\hline Predictive variables & Predicted variables & $R$ & $R$ Square & $B$ & Beta & $F$ & $T$ \\
\hline \multirow[t]{6}{*}{ Hostility } & Insomnia & .268 & .072 & 2.121 & .268 & 7.054 & 2.656 \\
\hline & Hypersomnia & .243 & .059 & .987 & .243 & 5.710 & 2.390 \\
\hline & Interrupted sleep & .225 & .051 & 1.174 & .225 & 4.870 & 2.207 \\
\hline & Nightmare disorder & .315 & .099 & 1.510 & .315 & 10.053 & 3.171 \\
\hline & Sleep walking disorder & .242 & .059 & 1.051 & .242 & 5.658 & 2.379 \\
\hline & Total sleep disorder & .275 & .076 & 7.796 & .275 & 7.453 & 2.730 \\
\hline \multirow[t]{6}{*}{ Phobic anxiety } & Insomnia & .380 & .144 & 2.615 & .380 & 15.358 & 3.919 \\
\hline & Interrupted sleep & .318 & .101 & 1.440 & .318 & 10.215 & 3.196 \\
\hline & Nightmare disorder & .403 & .162 & 1.680 & .403 & 17.645 & 4.201 \\
\hline & Night dismay & .275 & .076 & 1.326 & .275 & 7.459 & 2.731 \\
\hline & Sleep walking disorder & .253 & .064 & .958 & .253 & 6.249 & 2.500 \\
\hline & Total sleep disorder & .354 & .125 & 8.718 & .354 & 12.996 & 3.605 \\
\hline \multirow[t]{5}{*}{ Paranoid ideation } & Insomnia & .250 & .063 & 2.136 & .250 & 6.056 & 2.467 \\
\hline & Hypersomnia & .243 & .059 & 1.066 & .243 & 5.718 & 2.391 \\
\hline & Interrupted sleep & .230 & .053 & 1.292 & .230 & 5.082 & 2.254 \\
\hline & Sleep walking disorder & .225 & .051 & 1.056 & .225 & 4.870 & 2.207 \\
\hline & Total sleep disorder & .211 & .045 & 6.457 & .211 & 4.248 & 2.061 \\
\hline \multirow[t]{6}{*}{ Psychoticism } & Insomnia & .363 & .132 & 4.174 & .363 & 13.823 & 3.718 \\
\hline & Hypersomnia & .233 & .054 & 1.374 & .233 & 5.206 & 2.282 \\
\hline & Interrupted sleep & .220 & .048 & 1.662 & .220 & 4.609 & 2.147 \\
\hline & Nightmare disorder & .330 & .109 & 2.296 & .330 & 11.107 & 3.333 \\
\hline & Sleep walking disorder & .362 & .131 & 2.284 & .362 & 13.708 & 3.702 \\
\hline & Total sleep disorder & .324 & .105 & 13.329 & .324 & 10.643 & 3.262 \\
\hline
\end{tabular}

(Value $=.01 \& .001$ )

By correlating the different stressors (whether social or physical) which are being faced by breast cancer patients with different study domains as depression and anxiety and sleep disorders, we conclude that there is a positive correlation between all, these stressors, and the different study domains. The association between physical and social symptoms burden and the incidence of depression and anxiety in breast cancer patients were done by [30].

\section{Conclusions}

Prevalence of depression and anxiety among breast cancer patients poses a challenge to the treatment of such patients. Misdiagnosis and mismanagement lead to poor treatment outcomes of both cancer disease and psychiatric disorders with much poorer quality of life. Also, the higher prevalence of sleep disorders poses both mental and physical stress upon those patients with depilating disorder, which again is closely associated with depression and anxiety.

\section{Study limitation}

Factors such as effect of radiotherapy and chemotherapy on the sleep could not be excluded in the current study. Also, those factors may interfere with the development of other psychiatric manifestation. Larger scale study is needed to exclude such factors.

\section{Abbreviations}

SDS: Sleep disorder scale; GAD: Generalized anxiety disorder; SCL: Symptom checklist; SPSS: Statistical package for social science; BDI: Beck's depression inventory

\section{Acknowledgements}

Not applicable

Authors' contributions

R. H. contributed in study design, interpretation of the data, and preparing and revising the manuscript, also, he is the corresponding author. D.H. contributed in study design, assessing, interviewing the patients, collecting, and analyzing and interpreting the data. All authors have read and approved the manuscript

\section{Funding}

The current study was not supported by any national or international institution or organization. 


\section{Availability of data and materials}

The data sets generated and/or analyzed during the current study are available from the corresponding author on reasonable request.

\section{Ethics approval and consent to participate}

All procedures performed in studies involving human participants were in accordance with the ethical standards of the institutional and/or national research committee and with the 1964 Helsinki Declaration and its later amendments or comparable ethical standards. The current study was also approved by faculty of medicine, Assiut University Ethical Committee (reference number is not available).

Informed consent was obtained from all individual participants included in the study.

\section{Consent for publication}

All authors consenting for publication.

\section{Competing interests}

Authors declare that they have no competing interests.

\section{Author details}

'Department of Neurology and Psychiatry, Assiut University Hospitals, Box 71516, Assiut, PO, Egypt. ${ }^{2}$ Faculty of Arts, Assiut University, Assiut, Egypt.

Received: 9 November 2020 Accepted: 7 February 2021

Published online: 24 February 2021

\section{References}

1. Berger AM, Parker KP, Young-McCaughan S et al (2005) Sleep wake disturbances in people with cancer and their caregivers: state of the science. Oncol Nurs Forum 32:E98eE126

2. Mystakidou K, Parpa E, Tsilika E et al (2007) Sleep quality in advanced cancer patients. J Psychosom Res 62:527e533

3. Savard J, Morin CM (2001) Insomnia in the context of cancer: a review of a neglected problem. J Clin Oncol 19:895e908

4. Savard J, Simard S, Blanchet J, Ivers H, Morin CM (2001) Prevalence, clinical characteristics, and risk factors for insomnia in the context of breast cancer. Sleep 24:583e590

5. K. L. Rand, J. L. Otte, D. Flockhart, D. Hayes, A. M. Storniolo, V. Stearns, N. L. Henry, A. Nguyen, S. Lemler, J. Hayden, S. Jeter \&, J. S. Carpenter (2011) Modeling hot flushes and quality of life in breast cancer survivors, Climacteric, 14:1, 171 180, DOI.

6. Hayley MC, Williams L, Kennedy GA, Michael B, Sharon LB (March) Prevalence of excessive daytime sleepiness in a sample of the Australian adult population. Sleep Med 15(3):348-354

7. Cleeland CS, Zhao F, Chang VT et al (2013) The symptom burden of cancer: evidence for a core set of cancer-related and treatment-related symptoms from the Eastern Cooperative Oncology Group Symptom Outcomes and Practice Patterns study. Cancer 119(24):4333e40

8. Ness S, Kokal J, Fee-Schroeder K et al (2013) Concerns across the survivorship trajectory: results from a survey of cancer survivors. Oncol Nurs Forum 40(1):35e42

9. Loh KP, Pandya C, Zittel J et al (2017) Associations of sleep disturbance with physical function and cognition in older adults with cancer. Support Care Cancer 25(10):3161e9

10. Palesh O, Aldridge-Gerry A, Zeitzer JM et al (2014) Actigraphy- measured sleep disruption as a predictor of survival among women with advanced breast cancer. Sleep 37(5):837e42

11. Overcash J, Tan A, Patel K et al (2018) Factors associated with poor sleep in older women diagnosed with breast cancer. Oncol Nurs Forum 45(3): 359e71

12. Linden W, Vordermaier A, Mackenzie R, Greig D (2012) Anxiety and depression after cancer diagnosis: prevalence rates by cancer type, gender, and age. J Affect Disord 141:343-351

13. Cano A (2005) Control emocional, estilo represivo de afrontamiento $y$ cáncer: Ansiedad y cáncer. Psicooncología 2(1):71-80

14. Beck AT, Steer RA, Garbin MGJ (1988) Psychometric properties of the Beck Depression Inventory twenty-five years of evaluation. Clin Psychol Rev 8:77100

15. Gharyb AG 2000.Beck Depression Inventory-II (BDI-II),Arabic Exminer's Handbook,cairo Dar EL Anglo publishing
16. Derogatis LR, Savitz KL (2000) The SCL-90-R and the Brief Symptom Inventory (BSI) in primary care. In: Maruish ME (ed) Handbook of psychological assessment in primary care settings. Lawrence Erlbaum Associates, Mahwah, NJ, pp 297-334

17. Elbheriry, A E 2005: The symptom check list (SCL-90-R) ,Arabic Exminer's Handbook,cairo Dar EL Anglo publishing

18. Arnout, A Boshra 2013: Sleep disorder scale (S D S), Arabic Exminer's Handbook,cairo Dar EL Anglo publishing.

19. So WK, Marsh, G., Ling, W.M., Leung, F.Y., Lo, J.C.K., Yeung, M., et al., 2010. Anxiety, depression and quality of life among Chinese breast cancer patients during adjuvant therapy. Eur J Oncol Nurs 14, 17e22

20. Burgess C, Cornelius V, Love S, Graham J, Richards M, Ramirez A (2005) Depression and anxiety in women with early breast cancer: five year observational cohort study. Br Med J 330:702

21. Bredal IS (2016) Ekeberg. The stability of dispositional optimism in relation to receiving or not receiving a cancer diagnosis. Psychology 7:806-814

22. Taira N, Shimozuma K, Shiroiwa T, Ohsumi S, Kuroi K, Saji S et al (2011) Associations among baseline variables, treatment-related factors and health related quality of life 2 years after breast cancer surgery. Breast Cancer Res Treat 128:735e 747

23. Jovana Cvetković, Milutin Nenadović. Depression in breast cancer patients Psychiatry Res Volume 24030 June , 2016, Pages 343-347

24. Daniel C. McFarland, Kelly M. Shaffer, Amy Tiersten, Jimmie Holland. Physical symptom burden and its association with distress, anxiety, and depression in breast cancer. Psychosomatics 59:5, September/October 2018.

25. Andersen BL, DeRubeis RJ, Berman BS et al (2014) Screening, assessment, and care of anxiety and depressive symptoms in adults with cancer: an American Society of Clinical Oncology guideline adaptation. J Clin Oncol 32(15):1605-1619

26. Krueger RF, Finger MS (2001) Using item-response theory to understand comorbidity among anxiety and unipolar mood disorders. Psychol Assess 13:140-151

27. Angford DJ, Lee K, Miaskowski C (2012) Sleep disturbance interventions in oncology patients and family caregivers: a comprehensive review and meta-analysis. Sleep Med Rev 16(5):397-414

28. Win MR, Olmstead RE, Ganz PA, Haque R (2013) Sleep disturbance, inflammation and depression risk in cancer survivors. Brain Behav Immun 30(Suppl):S58-S67

29. Harris B, Ross J, Sanchez-Reilly S (2014) sleeping in the arms of cancer: a review of sleeping disorders among patients with cancer. Cancer J 20(5): 299-305

30. Daniel C. McFarland, Kelly M. Shaffer, Physical symptom burden and its association with distress, anxiety, and depression in breast cancer. Psychosomatics Volume 59, Issue 5, September- October 2018, Pages 464471.

\section{Publisher's Note}

Springer Nature remains neutral with regard to jurisdictional claims in published maps and institutional affiliations.

\section{Submit your manuscript to a SpringerOpen ${ }^{\circ}$ journal and benefit from:}

- Convenient online submission

- Rigorous peer review

- Open access: articles freely available online

- High visibility within the field

- Retaining the copyright to your article

Submit your next manuscript at $\boldsymbol{\nabla}$ springeropen.com 